\title{
Lymphomatoid granulomatosis: report of a case
}

\author{
CW EDWARDS, ELIZABETH NYHOLM, J CHAPMAN
}

From the Departments of Histopathology and Thoracic Medicine, East Birmingham Hospital, Birmingham

In 1972 Liebow $^{1}$ defined lymphomatoid granulomatosis as an "angiocentric and angiodestructive lymphoreticular and granulomatous disease involving predominantly the lungs." Its clinical and radiological manifestations are similar to the limited form of Wegener's granulomatosis, ${ }^{2}$ but the cellular infiltrate is atypical and a lymphoma develops in a significant proportion. ${ }^{3}$ There are certain affinities with malignant midline reticulosis and immunoblastic lymphadenopathy. ${ }^{34}$ Although some 200 cases have been reported from North America and Australia, ${ }^{1235}$ there are very few in the European literature, three of which are British. ${ }^{6} 7$ This paper reports the fourth British case.

\section{Case report}

A lady of 42 years presented in May 1980 with a threemonth history of malaise, pleuritic pain, cough, and dyspnoea. There were clinical and radiological signs of small, bilateral pleural effusions. It was thought that she had an unresolved chest infection, and she was given a course of ampicillin.

Two months later she was admitted with a left parotid swelling and tender subcutaneous nodules on the legs. The liver and spleen were enlarged, and there was a right pleural effusion. A chest radiograph showed rounded opacities throughout both lung fields. The white count was $2.6 \times 10^{9} / 1$ with $28 \%$ lymphocytes. The ESR and lactate dehydrogenase were elevated, and smooth muscle antibodies were demonstrated. The antinuclear factor was weakly positive at 1 in 10 . The results of other laboratory tests were normal.

Biopsies of the lung, skin, and parotid showed extensive necrosis and a pleomorphic infiltrate involving blood vessels (fig 1). Some cells had large oval or irregular nuclei with an open chromatin pattern and a prominent nucleolus. There were moderate numbers of lymphocytes, together with other cells morphologically intermediate between lymphocytes and plasma cells. True plasma cells were rare. Intravascular thrombi were frequent and there was occasional fibrinoid necrosis.

Despite prednisolone and cyclophosphamide therapy, the patient continued to deteriorate. She developed conjunctival oedema, lachrymal gland swelling, and a seventh nerve palsy, all on the right side. There was electrocardiographic evidence of a right bundle branch block. Treatment was changed to levamisole, again with little effect. Six months after presentation she collapsed at home, and died shortly after readmission.

Address for reprint requests: Dr CW Edwards, Department of Histopathology, East Birmingham Hospital, Bordesley Green East, Birmingham B9 5ST.

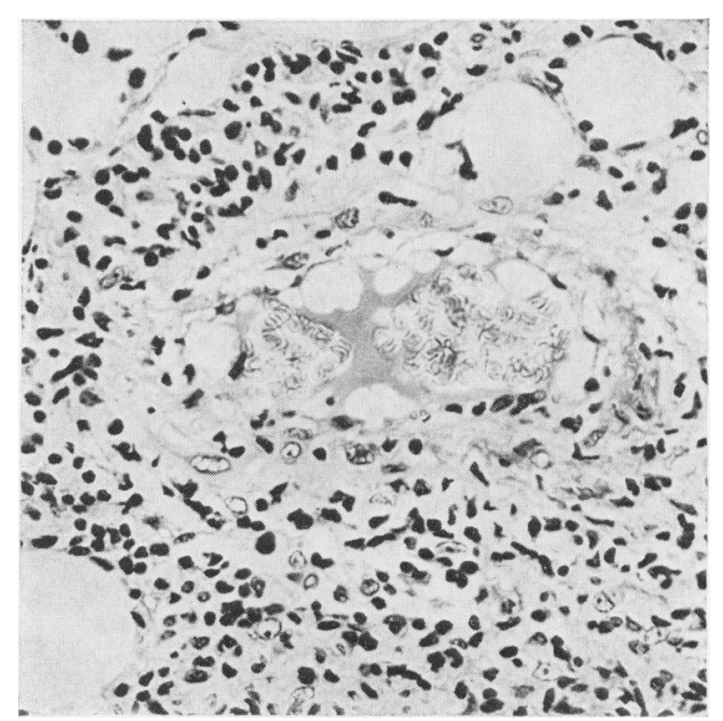

Fig 1 Skin biopsy. An infiltrate of large monocytic and smaller lymphocytoid cells is present in the wall of a vessel and adjacent fatty tissue. $H$ and $E, \times 275$.

\section{POSTMORTEM FINDINGS}

The pleura of the lower lobes was thickened and adherent. The basal segments of both lungs, the lingular segments, and the middle lobe were replaced by firm, grey-white necrotic material, surrounded by a narrow pink viable border. In the residual lung tissue there were scattered nodules up to $2 \mathrm{~cm}$ in diameter. The anteroseptal myocardium, the left parotid and both kidneys were infiltrated. The liver was enlarged to 2030 grams and had a smooth cut surface. The spleen was enlarged to 415 grams: its cut surface was deep purple, flecked with white. Other organs, including the brain, were normal. Lymph nodes were not enlarged.

Histologically, the infiltrate had changed, and appearances were now those of a lymphoplasmacytic lymphoma (fig 2). In the lungs neoplastic cells were sweeping through alveoli and the walls of blood vessels and bronchi. There was widespread necrosis. Tumour deposits were also present in the kidneys, skin, left parotid, spleen, and myocardium. Lymph nodes contained only a few tiny subcapsular aggregates of atypical cells. The liver showed congestive change and a non-specific reactive hepatitis. Other organs were normal. 


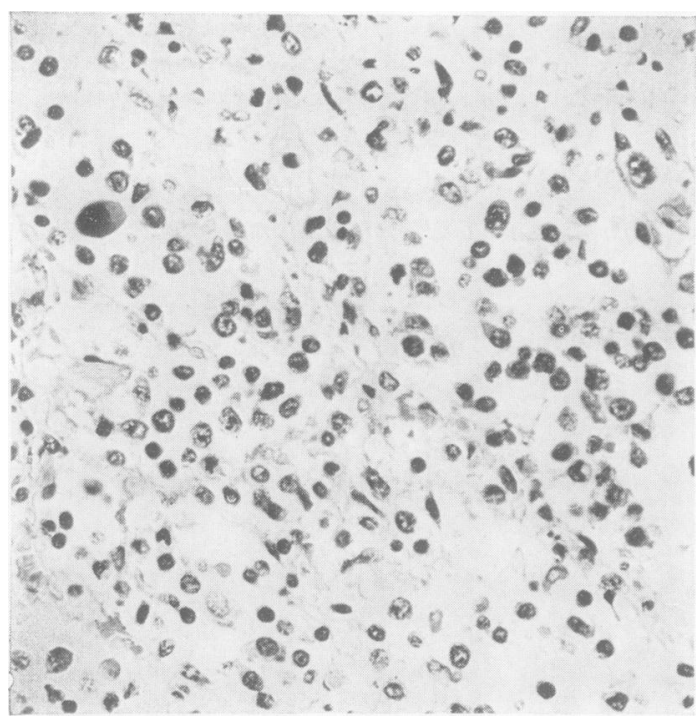

Fig 2 Postmortem lung infiltrated by a

lymphoplasmacytic lymphoma. $H$ and $E, \times 275$.

\section{Discussion}

Lymphomatoid granulomatosis most commonly occurs in the 30 to 60 year age group, with a slight male preponderance. ${ }^{13}$ Onset and progression are generally rapid. The usual presenting symptoms are cough, dyspnoea, malaise, fever, and arthralgia sometimes with haemoptysis. ${ }^{1-3}$ There may be a maculopapular rash or nodular ulcerating lesions of the legs, buttocks, and abdomen. Involvement of the central or peripheral nervous system is frequent and carries a bad prognosis. ${ }^{1}$ Dermatological or neurological manifestations may precede changes in the respiratory tract. Radiologically there are multiple, usually bilateral nodular masses in the lower and mid lung fields, which characteristically wax and wane: hilar lymphadenopathy is unusual. ${ }^{1}$ Haematological and biochemical changes are non-specific and unhelpful in diagnosis. ${ }^{1}$

The basic pathology is a proliferation of mononuclear cells, plasma cells, and lymphocytes which invade blood vessels and ultimately destroy them. ${ }^{1-3} 5$ The constantly changing pattern of the radiological lesions is $\vec{Z}$ the result of concurrent infiltration, infarction, necrosis, and partial resolution. A lymphoma, usually of plasmacytoid or immunoblastic type, develops in up to $20 \%$ of cases. $^{35}$

The treatment of choice is uncertain at present. A $\overparen{\mathbb{D}}$ number of combinations of steroids and cytotoxic drugs have been tried, none having been found particularly effective, although occasional lung remissions have been $\overrightarrow{0}$ reported. ${ }^{135}$ Radiotherapy, combined with local excision, appears to offer the best hope of a cure. ${ }^{8} 9$

The aetiology is unknown, but there is some evidence that immune suppression or long continued antigenic stimulus in an abnormal host may be precipitating $\omega$ factors. ${ }^{3}$ Immunocytochemical and ultrastructural studies . indicate that there is an abnormal proliferation of B cells, which may progress to malignant lymphoma. ${ }^{10}$ It is $\overrightarrow{\vec{\omega}}$ perhaps significant that most of the reported cases are 0 from North America or Australia, which may reflect the geographical incidence of an infective agent.

\section{References}

' Liebow AA, Carrington CRB, Friedman PJ. Lymphomatoid granulomatosis. Hum Pathol 1972;3:457-558.

${ }^{2}$ Liebow AA. Pulmonary angiitis and granulomatosis. $\mathrm{Am}$ Rev Respir Dis 1973;108:1-18.

${ }^{3}$ Katzenstein AL, Carrington CB, Liebow AA. Lymphomatoid granulomatosis. A clinicopathological study of 152 cases. Cancer 1979;43:360-73.

${ }^{4}$ DeRemee RA, Weiland LH, McDonald TJ. Respiratory vasculitis. Mayo Clin Proc 1980;5:492-8.

${ }^{5}$ Saldana M, Patchefsky AS, Israel HI, Atkinson CW. Pulmonary angiitis and granulomatosis. The relationship between histological features, organ involvement and response to treatment. Hum Pathol 1977;8:391-409.

${ }^{6}$ MacDonald DM, Sarkany I. Lymphomatoid granulomatosis. Clin Exp Dermatol 1976;1:163-73.

' Gibbs AR. Lymphomatoid granulomatosis - a condition with affinities to Wegener's granulomatosis and lym-

phoma. Thorax 1977;32:71-9.
${ }^{8}$ Fuller P, Hafermann D, Byrd R, Jenkins D. Use of 3 . irradiation in lymphomatoid granulomatosis. Chest $\delta$ $1978 ; 74: 105-6$.

${ }^{9}$ Shank BB, Kelley CD, Nisce LZ, Nori D. Radiation therapy in lymphomatoid granulomatosis. Cancer 1978; O 42:2572-80

${ }^{10}$ Bender BL, Jaffe R. Immunoglobulin production in lymphomatoid granulomatosis and relation to other "benign" lymphoproliferative disorders. Am J Clin N Pathol 1980;73:41-7. 